\title{
Nutritional compositions, polyphenolic profiles and antioxidant properties of pigmented rice varieties and adlay seeds enhanced by soaking and germination conditions
}

\author{
Iyiola Oluwakemi Owolabi, Bandhita Saibandith, Santad Wichienchot, Chutha \\ Takahashi Yupanqui
}

Interdisciplinary Graduate School of Nutraceutical and Functional Food (IGS-NFF), Prince of Songkla University, Hat-Yai, Songkhla 90112, Thailand

Corresponding author: Takahashi Yupanqui, Interdisciplinary Graduate School of Nutraceutical and Functional Food (IGS-NFF), Prince of Songkla University, Hat-Yai, Songkhla, 90112, Thailand

Submission Date: September 27 $7^{\text {th }}$ 2018, Acceptance Date: December $28^{\text {th }}, 2018$, Publication Date: December $30^{\text {th }}, 2018$

Citation: Owolabi I.O., Saibandith B., Wichienchot S., Yupanqui C.T. Nutritional compositions, polyphenolic profiles and antioxidant properties of pigmented rice varieties and adlay seeds enhanced by soaking and germination conditions. Functional Foods in Health and Disease 2018; 8(12): 561-578. DOI: https://doi.org/10.31989/ffhd.v8i12.564

\begin{abstract}
Background: Pigmented rice varieties are gaining interest due to their superior nutritional and phenolic properties compared to white rice varieties. With the rising risk of diabetes, cereals with higher protein contents should be consumed with rice. Adlay is one of the underutilized crops with higher protein contents and other functional properties. The germination process is one of the easy and innovative techniques for improving functional properties in seeds.
\end{abstract}

Objective: In this study, two pigmented rice varieties and adlay seeds were soaked ( $24 \mathrm{~h})$ and germinated for $12,24,36$, and $48 \mathrm{~h}$. The physicochemical properties, polyphenolic profiles, and the antioxidant activities of these samples were evaluated.

Results: Purple rice (PR) demonstrated the highest values for polyphenolic contents, with 9 compounds detected for antioxidant activities. There were 6 compounds detected for red rice (RR). The adlay seeds had the least concentrations of phenolic compounds, with 6 compounds and higher nutritional properties identified. New compounds were synthesized. Among the rice samples, $24 \mathrm{~h}$ soaking $\left(\mathrm{S}_{24}\right)$ gave the best results for phenolic and antioxidant properties, with $24 \mathrm{~h}$ germination in adlay seeds. $48 \mathrm{~h}$ germination yielded better results for the nutritional values in all the samples. 
Conclusion: The present study demonstrates how the process of soaking is a cheap and less time-consuming process of improving bioactive compounds and antioxidant activities in pigmented rice varieties and adlay seeds.

Keywords: polyphenols, antioxidant, pigmented rice, adlay, germination.

\section{INTRODUCTION}

Germination is a cheap, easy, innovative, and effective method of enhancing the nutritive composition in cereals rice compared to other techniques of improving quality of cereals [1]. Before the germination process is carried out, grains are soaked in water for a few days, softening the kernel and stimulating germination. Germination enhances some changes biochemically, triggering some inactive enzymes responsible for the breakdown of large molecular substances. This leads to the synthesis of some bioactive compounds and increasing the bioavailability of nutrients and absorption [2]. In Asian countries, the germination of rice is becoming more popular to the various nutritional advantages. Germinated grains, especially rice, are known to be good sources of some compounds beneficial to human health. These include vitamin B, E, $\beta$ - carotene, $\gamma$ - oryzanol, anthocyanin, and Gamma-aminobutyric acid (GABA).

Rice (Oryza sativa L.) is predominantly consumed across Asian countries among other cereals. Rice accounts for $50 \%$ of the total cereal production worldwide [3]. Pigmented rice varieties with purple (which is also known as black rice, forbidden rice, king's rice, etc.), red, or brown pericarp are popular for their surpassing nutritive contents and higher antioxidant properties than the white cultivars $[4,5]$. These cultivars have higher amounts of anthocyanins, phenolic compounds, and other bioactive compounds [6,7]. The people who consume pigmented rice varieties are at low risk for diabetes, heart diseases, cancer, etc. [8]. Similarly, the intake of germinated colored rice varieties is capable of controlling postprandial glucose contents in the blood while balancing the secretion of insulin in subjects with high blood glucose contents [9].

Other cereals improved by the process of germination is adlay (Coix lachryma-jobi L.), which is also known as Chinese pearl barley or Job's tears. Adlay is distributed throughout China, Japan, and Thailand. This cereal is a food and a useful ingredient in medicine [10]. In addition to having many of the same bioactive components present in rice, adlay also contains coixol, coixenolide, and bioactive peptides [11]. Adlay has been investigated for it physiological and pharmacological activities, including anti-inflammation, anti-cancer, and anti-analgesic activities [12]. Some modern studies have reported that adlay seeds have several health benefits which include the potential to prevent tumor formation [13], the ability to reduce inflammation [14], and supporting immune system regulation [15]. Adlay is also widely recognized as a food supplement which can help decrease serum cholesterol and triglycerides, in addition to reducing liver lipids by increasing lipid excretion [16].

The rise in the consumption of ready-to-eat rice porridge in Asian countries including Thailand poses a great concern with respect to the consequential effects on the postprandial blood glucose contents in subjects concerned. Alternatively germinated pigmented rice varieties can be prepared together with adlay (also known as rice-job's tears "congee") as 
breakfast. The increased bioactive components from these grains with higher protein and fat contents from Adlay may help in reducing the incidence of some metabolic disorders.

Purple rice (Khao neaw dam), red rice (Cho khing), and adlay (Look-Dei) are less known and consumed, especially adlay. Adlay is an underutilized crop in Thailand and Asia. Detailed information on their chemical, antioxidants properties, phenolic composition, and profile are limited. Therefore, the aim of this study was to enhance the polyphenolic contents and antioxidant properties of these pigmented rice and adlay under soaking and different germination conditions.

\section{MATERIALS AND METHODS}

\section{Sample preparation, soaking and germination}

Rough rice samples (Khao neaw dam and Cho khing) and adlay (Look-Dei) (Figure 1) were obtained from Southern Thailand (Songkhla Province). The grains were soaked in $2.5 \%$ sodium hypochlorite solution $(1: 5 \mathrm{w} / \mathrm{v})$ at $1-5 \%$ concentration for $5 \mathrm{~min}$ and drained. The purpose is to destroy or remove surface fungi and bacteria without killing internal organs. This was followed by washing the disinfected seed with distilled water in order to remove excess sodium hypochlorite.

The grains were soaked in distilled water (seed: water ratio, $1.5 \mathrm{w} / \mathrm{v}$ ) at ambient temperature $\left(30 \pm 5^{\circ} \mathrm{C}\right)$ for $24 \mathrm{~h}$ with the water changed every $8 \mathrm{~h}$ so that mold growth does not take over. After $24 \mathrm{~h}$, the grains were collected for further process. For the germination process, the soaked seeds were placed in germination trays covered with moist cheese cloth and allowed to germinate for $12,24,36$, and $48 \mathrm{~h}$ at $37^{\circ} \mathrm{C}$. Relative humidity was around $66 \%$ in a closed system. At the end of the germination period, the seeds were oven dried at $80^{\circ} \mathrm{C}$ for $5 \mathrm{~h}$, followed by de-husking. The de-husked seeds were grounded into a fine powder by 40 -mesh sieve and stored at $-20^{\circ} \mathrm{C}$ for further analysis.

\section{Chemical compositions}

The moisture, protein, fat, carbohydrate, ash, and fiber contents of both germinated and ungerminated samples were analyzed following the method of Association of Official Analytical Chemists (AOAC) [17]. After determination of nitrogen content using micro-Kjeldahl apparatus, protein contents were calculated as N x 5.95 for rice and N x 5.7 for Job's tears.

The crude fat was determined using Soxhlet apparatus. The ash content was determined by incinerating the sample in a furnace set at $600^{\circ} \mathrm{C}$. Finally, the carbohydrate contents were determined using the following formula:

$100 \%$ - protein content - moisture content - ash content - crude fat content.

\section{Extraction of phenolic compounds}

Phenolic compounds in both germinated and un-germinated samples were extracted with $80 \%$ methanol by centrifugation (Hatachi CR22GIII) at 10,000 x $g$ for $20 \mathrm{~min}$. The extraction was carried out three times with the supernatants pooled and evaporated to $\sim 10 \mathrm{~mL}$ at $35^{\circ} \mathrm{C}$ under 
reduced pressure to remove the solvent. The evaporated samples were lyophilized to dryness and stored at $-20^{\circ} \mathrm{C}$ for further analysis.

\section{Phytochemical screening}

Freeze dried powder of germinated and un-germinated samples were tested for the presence of numerous phytochemical constituents following the methods described by Sofowora [18] and Harborne [19]. All analyses were performed in triplicate.

\section{Total extractable phenolic content (TPC)}

The total extractable phenolic contents of the extracts were measured using a Folin-Ciocalteu method from Singleton and Rossi [20]. 20 $\mathrm{L}$ of the extract was added to 96-well micro-plate. Next, $100 \mu \mathrm{L}$ of Folin-Ciocalteu reagent $(10 \% \mathrm{v} / \mathrm{v})$ and $80 \mu \mathrm{L}$ of $\mathrm{Na}_{2} \mathrm{CO}_{3}(7.5 \% \mathrm{w} / \mathrm{v})$ were added and mixed thoroughly. After incubation for $30 \mathrm{~min}$ in the dark at ambient temperature, the absorbance was measured at $765 \mathrm{~nm}$ using the micro-plate reader. The total phenolic content was expressed as mg Gallic Acid Equivalent (GAE)/g DM.

\section{Total extractable flavonoid content (TFC)}

For the assay of TFC, $15 \mu \mathrm{L}$ of extract was mixed with $125 \mu \mathrm{L}$ DI water and $10 \mu \mathrm{L}$ of $5 \%$ sodium nitrite. This mixture was incubated at room temperature for $6 \mathrm{~min}$, after which $10 \mu \mathrm{L}$ of $10 \%$ aluminum chloride was added and incubated for $5 \mathrm{~min}$. Finally, $50 \mu \mathrm{L}$ of $1 \mathrm{M} \mathrm{NaOH}$ was added, followed by incubation at room temperature for $15 \mathrm{~min}$. The absorbance of the well-mixed mixture was measured at $510 \mathrm{~nm}$. TFC was calibrated with a standard curve of Catechin and expressed as Catechin Equivalent (mg CE/g DM).

\section{Antioxidant activities}

\section{DPPH radical scavenging activity}

2,2-diphenyl-1-picryl hydrazyl (DPPH) radical scavenging activity was determined using the modified method of Brand-Williams et al. [21] $150 \mu \mathrm{L}$ of the extract was added with $150 \mu \mathrm{L}$ of $0.2 \mathrm{mM}$ DPPH in $95 \%$ ethanol. The mixture was incubated in the dark for $30 \mathrm{~min}$ and the absorbance was determined at $517 \mathrm{~nm}$ using the micro-plate reader. The activity was reported as mg Trolox equivalent (TE/g DM).

\section{ABTS radical scavenging activity}

2,2-azino-bis-3-ethylbenzthiazoline-6-sulphonic acid (ABTS) assay was determined following the method of Arnao et al. [22]. The stock solutions of $7.4 \mathrm{mM}$ ABTS solution and $2.5 \mathrm{mM}$ $\mathrm{K}_{2} \mathrm{~S}_{2} \mathrm{O} 8$ solution were prepared. The ABTS radical solution was generated by mixing both stock solutions in equal quantities and allowing them to react for $12 \mathrm{~h}$ at room temperature in the dark. The radical solution was diluted to obtain an absorbance of $1.1 \pm 0.02$ at $734 \mathrm{~nm}$ before performing the assay. $15 \mu \mathrm{L}$ of an extract was mixed with $285 \mu \mathrm{L}$ of ABTS radical solution and 
left at room temperature for $2 \mathrm{~h}$ in the dark. The absorbance was measured at $734 \mathrm{~nm}$ using the micro-plate reader. The activity was reported as Trolox equivalent (TE)/g DM.

\section{Ferric reducing antioxidant power (FRAP)}

The ferric reducing antioxidant power (FRAP) assay was performed according to the method of Benzie and Strain [23]. FRAP solution was freshly prepared from the mixture of $300 \mathrm{mM}$ acetate buffer pH 3.6, $10 \mathrm{mM}$ TPTZ (2, 4, 6- tripyridyl-s-triazine) solution in $40 \mathrm{mM} \mathrm{HCl}$, and $20 \mathrm{mM} \mathrm{FeCl}_{3} .6 \mathrm{H}_{2} \mathrm{O}$ solution at the ratio $10: 1: 1(\mathrm{v} / \mathrm{v} / \mathrm{v})$, and then warmed at $37^{\circ} \mathrm{C}$ for $30 \mathrm{~min}$ before use. $15 \mu \mathrm{L}$ of an extract was added with $285 \mu \mathrm{L}$ of FRAP solution and stand for $30 \mathrm{~min}$ in the dark. The absorbance was read at $593 \mathrm{~nm}$ using micro-plate reader. The activity was reported as mg Trolox equivalent (TE/g DM).

\section{Quantification of phenolic profiles un-germinated, soaked and germinated sample extracts}

Phenolic compounds in the germinated and un-germinated extracts were estimated by reversedphase HPLC. All samples were filtered through a $0.22 \mu \mathrm{m}$ pore size syringe-driven filter before injection. A $20 \mu \mathrm{L}$ aliquot of a sample solution was separated using Agilent HPLC technology system equipped with a diode array detector on an Agilent Eclipse XDB-C18, 5 $\mu$ m diameter, $4.6 \mathrm{~mm} \times 250 \mathrm{~mm}$ analytical column. The mobile phase consisted of Methanol (A) and purified water (HPLC grade) with $1 \%$ Formic acid (FA) at a flow rate of $0.8 \mathrm{~mL} / \mathrm{min}$. Gradient elution was performed as the following: from 0 to $10 \mathrm{~min}$, linear gradient from 1 to $10 \%$ solvent $\mathrm{A}$; from 10 to $20 \mathrm{~min}, 25 \%$ solvent $\mathrm{A}$; from 20 to $30 \mathrm{~min}, 60 \%$ solvent $\mathrm{A}$; and from 30 to $40 \mathrm{~min}$, $70 \%$ solvent $\mathrm{A}$. The stop time was $5 \mathrm{~min}$ in order to allow proper conditioning of the column before next injection. Column temperature was set at $25^{\circ} \mathrm{C}$. Phenolic compounds in the samples were evaluated at wavelengths of 254,280 , and $300 \mathrm{~nm}$. Each compound was identified by its corresponding retention time and also by spiking with standards in the same conditions.

\section{Statistical analysis}

All data from the results of this study were statistically analyzed by one-way ANOVA using a completely randomized design. The mean values were analyzed by Turkey test for a multicomparison of means and correlation analysis using Pearson correlation. Statistical analyses were carried out using the SPSS statistical software (SPSS, Inc., Chicago. IL).

\section{RESULTS AND DISCUSSION}

\section{Water hydration characteristics of $P R, R R$, and adlay seeds}

The hydration characteristics of the cereals evaluated are shown in Figure 1. Water absorption in the PR increased rapidly during the $24 \mathrm{~h}$ soaking up to four times and almost remained stable during the germination period. For the RR, the rate of water hydration increases about three times, drops after $24 \mathrm{~h}$ soaking, and becomes stable until $48 \mathrm{~h}$ germination where it increases slightly. The least moisture contents were observed in adlay seeds where the water absorption 
increases throughout the soaking and germination periods. The moisture content in the seeds are correlated with the percentage of germination and quality. The difference in the moisture contents in the seeds could be due to differences in seeds and varieties [24].

\section{Changes in proximate composition during soaking and germination conditions}

The proximate compositions of the two pigmented rice varieties and adlay are presented in Table 1. Germination process starts with the imbibition of water in the seeds. The moisture content increased across the samples. During the soaking germination periods, purple rice (PR) showed the highest moisture content at $48 \mathrm{~h}$ germination (44.64 g/100g). PR is known as waxy rice with a soft kernel which may allow more rapid imbibition of water during soaking and germination. The values for the protein contents were similar for PR, while the values increased during germination in red rice (RR) and adlay with ranges between $3.52-10.46 \mathrm{~g} / 100 \mathrm{~g}$ and $9.90-17.37 \mathrm{~g} / 100 \mathrm{~g}$ in $\mathrm{RR}$ and adlay respectively. The process of germination enables the activation of several enzymes that can synthesize some proteins via a series of chemical and biological reactions. Similarly, some proteins get hydrolyzed by protease enzymes. In other words, there is a process of dynamic regulation which influences the protein contents during germination [25].

The PR and adlay gave the highest protein contents at $48 \mathrm{~h}(11.39$ and $17.37 \mathrm{~g} / 100 \mathrm{~g})$ which could be an interesting source of protein in food products. The fat content increased significantly in adlay during germination $(4.34-6.63 \mathrm{~g} / 100 \mathrm{~g})$ but decreases at first and increases later up to $48 \mathrm{~h}$ in PR (3.02 g/100g). Meanwhile, the fat contents in RR were similar through all the germination periods. The fat components in rice seed are located around the aleurone layer of the rice bran. During the milling process, some portions of the fat could be lost as the bran is removed. Additionally, according to Hettiarachchy et al. [26] the fat components of the rice grain may contain some triacylglycerol that could be used up as a source of energy for the embryo during germination.

However, the fat contents of the purple rice variety were similar to the studies of Juliano [27] who reported fat contents of black rice $(2.8-3.7 \%)$. For adlay, the protein and fat contents were higher than the values in the study carried out by Chaisiricharoenkul et al. [28], who reported that protein contents in whole grain adlay range between 13.54 to $16.85 \%$ and between 4.86 to $5.35 \%$ for lipid. The crude fiber in the seeds also increased progressively. The presence of the bran layer in the rice varieties and the outer coat in adlay seeds contributes to the fiber contents [29].

In all three samples, the carbohydrate contents were reduced during the germination periods, which may be a result of degradation in order to provide energy for the growth of the embryo. The high energy values obtained in adlay seeds were influenced by higher crude protein and fat contents. The values obtained are within the values obtained by Sompong et al [30] and Oko et al [31]. The ash contents were also similar during soaking and germination period. These results demonstrate that the mineral contents in the seeds were intact and did not leach significantly during these periods. 
Changes in the phenolic contents during soaking and germination conditions

The total phenolic and total flavonoid contents (TPC and TFC) of both germinated and ungerminated samples are illustrated in Figure 2 (A \& B). In PR, TFC was observed to slightly decrease during germination compared to the control $(\mathrm{P}<0.05)$. A similar trend was also observed in RR except for the higher TPC (7.93 $\mathrm{mg} \mathrm{GAE} \mathrm{g}^{-1}$ ) during the $24 \mathrm{~h}$ soaking period $\left(\mathrm{S}_{24}\right)$ compared with control $\left(6.93 \mathrm{mg} \mathrm{GAE} \mathrm{g}^{-1}\right)$. In contrast, germination increased the total phenolic contents in soaked and germinated adlay seeds. Additionally, for the TFC, values increased with soaking and germination in all three samples except for RR where significant

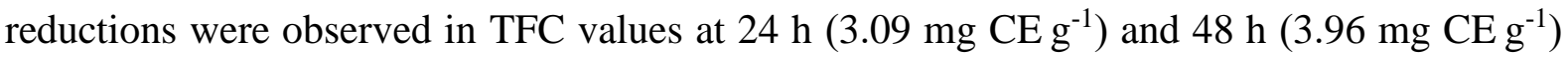
germination periods compared with the control (4.17 $\left.\mathrm{mg} \mathrm{CE} \mathrm{g}^{-1}\right)$. Secondary metabolites such as phenolic acids, flavonoids, condensed tannins, and others are crucial substances produced during germination. These substances are mainly synthesized via the shikimate pathway and also the phenylpropanoid biosynthesis pathway [25]. During the soaking and germination process, L-phenylpropanoid is converted to cinnamic acid by phenylalamine ammonialyase (PAL). This leads to the synthesis of some phenolic acids including ferulic acid, caffeic acid, and $p$-coumaric.

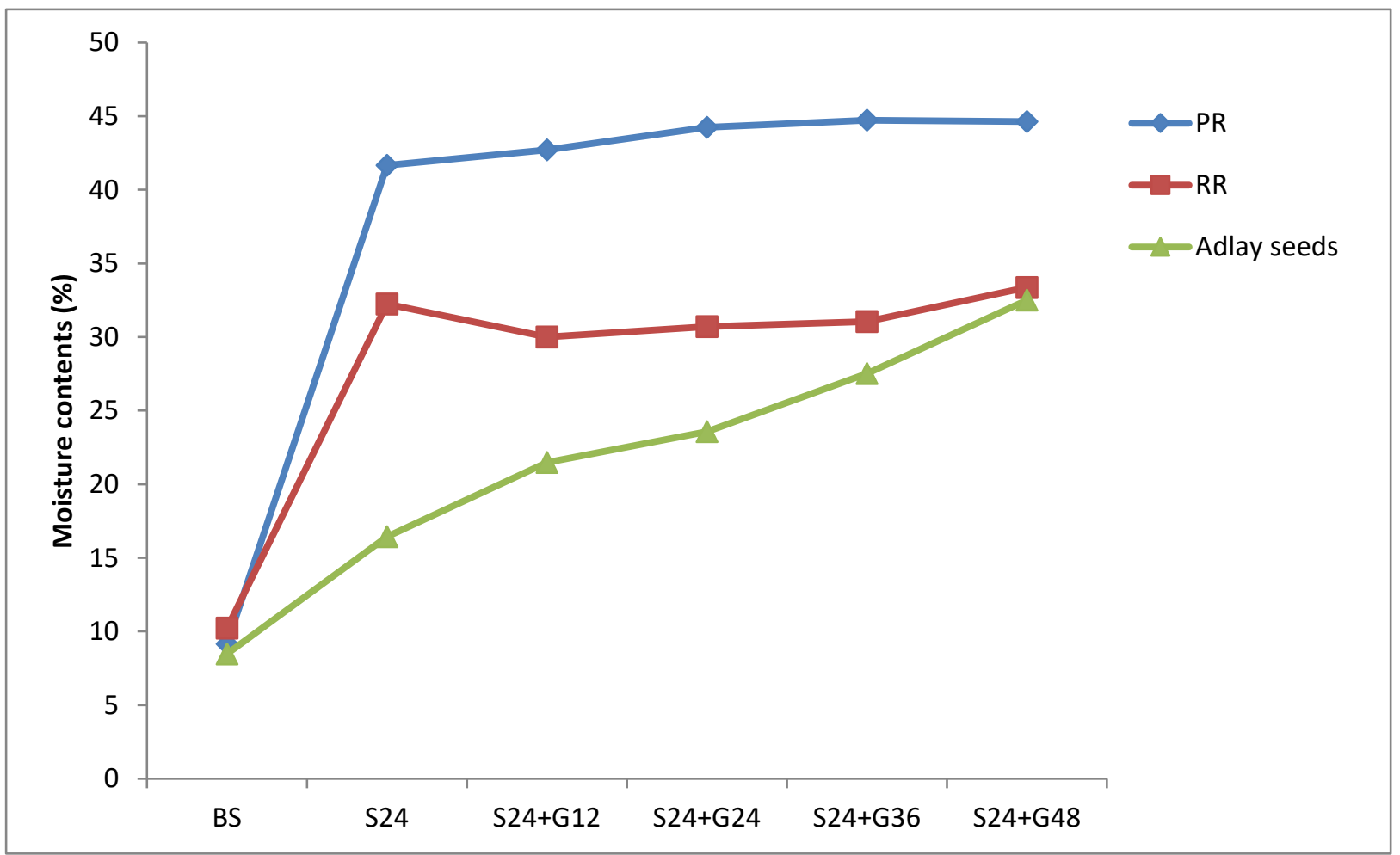

Figure 1. Rate of water hydration in PR, RR, and adlay seeds before soaking, after soaking and during germination at $12,24,36$, and $48 \mathrm{~h}$. BS-Before soaking; $\mathrm{S}_{24-} 24 \mathrm{~h}$ soaking; $\mathrm{S}_{24}+\mathrm{G}_{12-}$ $24 \mathrm{~h}$ soaking $+12 \mathrm{~h}$ germination; $\mathrm{S}_{24}+\mathrm{G}_{24}-24 \mathrm{~h}$ soaking $+24 \mathrm{~h}$ germination; $\mathrm{S}_{24}+\mathrm{G}_{36^{-}}-24 \mathrm{~h}$ soaking +36 h germination; $\mathrm{S}_{24}+\mathrm{G}_{48}-24 \mathrm{~h}$ soaking $+48 \mathrm{~h}$ germination. PR- Purple Rice; $\mathrm{RR}-$ Red Rice. db- dry basis. 
Table 1. Sample and treatments description

\begin{tabular}{|c|c|c|c|c|}
\hline Sample & Sample code & Treatments & Soaking time & Germination time \\
\hline \multirow[t]{6}{*}{ Purple rice } & PR & Raw sample (BS) & $0 \mathrm{~h}$ & $\mathrm{Oh}$ \\
\hline & & $\mathrm{S}_{24}$ & $24 \mathrm{~h}$ & $\mathrm{Oh}$ \\
\hline & & $\mathrm{S}_{24}+12 \mathrm{~h}$ germination & $24 \mathrm{~h}$ & $12 \mathrm{~h}$ \\
\hline & & $\mathrm{S}_{24}+24 \mathrm{~h}$ germination & $24 \mathrm{~h}$ & $24 \mathrm{~h}$ \\
\hline & & $\mathrm{S}_{24}+36 \mathrm{~h}$ germination & $24 \mathrm{~h}$ & $36 \mathrm{~h}$ \\
\hline & & $\mathrm{S}_{24}+48 \mathrm{~h}$ germination & $24 \mathrm{~h}$ & $48 \mathrm{~h}$ \\
\hline \multirow[t]{6}{*}{ Red rice } & $\mathrm{RR}$ & Raw sample (BS) & $0 \mathrm{~h}$ & Oh \\
\hline & & $\mathrm{S}_{24}$ & $24 \mathrm{~h}$ & $\mathrm{Oh}$ \\
\hline & & $\mathrm{S}_{24}+12 \mathrm{~h}$ germination & $24 \mathrm{~h}$ & $12 \mathrm{~h}$ \\
\hline & & $\mathrm{S}_{24}+24 \mathrm{~h}$ germination & $24 \mathrm{~h}$ & $24 \mathrm{~h}$ \\
\hline & & $\mathrm{S}_{24}+36 \mathrm{~h}$ germination & $24 \mathrm{~h}$ & $36 \mathrm{~h}$ \\
\hline & & $\mathrm{S}_{24}+48 \mathrm{~h}$ germination & $24 \mathrm{~h}$ & $48 \mathrm{~h}$ \\
\hline \multirow[t]{6}{*}{ Adlay } & adlay & Raw sample (BS) & $0 \mathrm{~h}$ & $\mathrm{Oh}$ \\
\hline & & $\mathrm{S}_{24}$ & $24 \mathrm{~h}$ & $\mathrm{Oh}$ \\
\hline & & $\mathrm{S}_{24}+12 \mathrm{~h}$ germination & $24 \mathrm{~h}$ & $12 \mathrm{~h}$ \\
\hline & & $\mathrm{S}_{24}+24 \mathrm{~h}$ germination & $24 \mathrm{~h}$ & $24 \mathrm{~h}$ \\
\hline & & $\mathrm{S}_{24}+36 \mathrm{~h}$ germination & $24 \mathrm{~h}$ & $36 \mathrm{~h}$ \\
\hline & & $\mathrm{S}_{24}+48 \mathrm{~h}$ germination & $24 \mathrm{~h}$ & $48 \mathrm{~h}$ \\
\hline
\end{tabular}


Table 2. Physicochemical properties of raw samples, soaked and germinated PR, RR and adlay at 0, 12, 24, 36, and $48 \mathrm{~h}$

\begin{tabular}{|c|c|c|c|c|c|c|c|c|}
\hline Samples & Treatments & Moisture & Crude Protein & Total Fat & Ash & Crude Fiber & Total carbohydrate & Energy (Kcal/100g) \\
\hline \multirow[t]{6}{*}{ PR } & BS & $9.16 \pm 0.08^{\mathrm{d}}$ & $10.28 \pm 0.82^{\mathrm{a}}$ & $2.23 \pm 0.40^{\mathrm{b}}$ & $0.99 \pm 0.01^{\mathrm{a}}$ & $0.78 \pm 0.13^{\mathrm{d}}$ & $77.33 \pm 0.46^{\mathrm{a}}$ & $370.51 \pm 0.09^{\mathrm{a}}$ \\
\hline & $\mathrm{S}_{24}$ & $41.66 \pm 0.18^{c}$ & $11.31 \pm 0.34^{\mathrm{a}}$ & $1.92 \pm 0.03^{\mathrm{b}}$ & $1.00 \pm 0.06^{\mathrm{a}}$ & $0.86 \pm 0.10^{c}$ & $44.12 \pm 0.23^{\mathrm{b}}$ & $239.00 \pm 0.10^{\mathrm{b}}$ \\
\hline & $\mathrm{S}_{24}+\mathrm{G}_{12}$ & $42.71 \pm 0.39^{b}$ & $10.42 \pm 0.60^{\mathrm{a}}$ & $3.60 \pm 0.36^{\mathrm{a}}$ & $1.00 \pm 0.00^{\mathrm{a}}$ & $0.88 \pm 0.16^{\mathrm{c}}$ & $42.27 \pm 1.16^{\mathrm{c}}$ & $243.16 \pm 0.02^{\mathrm{b}}$ \\
\hline & $\mathrm{S}_{24}+\mathrm{G}_{24}$ & $44.24 \pm 0.18 \mathrm{a}$ & $10.28 \pm 0.54^{\mathrm{a}}$ & $1.97 \pm 0.75^{\mathrm{b}}$ & $0.99 \pm 0.01^{\mathrm{a}}$ & $0.94 \pm 0.06^{\mathrm{b}}$ & $42.52 \pm 0.46^{\mathrm{bc}}$ & $228.93 \pm 0.06^{\mathrm{b}}$ \\
\hline & $\mathrm{S}_{24^{+}} \mathrm{G}_{36}$ & $44.72 \pm 0.50^{\mathrm{a}}$ & $10.78 \pm 0.92^{\mathrm{a}}$ & $2.38 \pm 0.28^{\mathrm{b}}$ & $0.99 \pm 0.01^{\mathrm{a}}$ & $0.98 \pm 0.11^{\mathrm{b}}$ & $41.12 \pm 0.14^{\text {cd }}$ & $229.02 \pm 0.02^{\mathrm{b}}$ \\
\hline & $\mathrm{S}_{24}+\mathrm{G}_{48}$ & $44.64 \pm 0.62^{\mathrm{a}}$ & $11.39 \pm 0.48^{\mathrm{a}}$ & $3.02 \pm 0.28^{\mathrm{ab}}$ & $0.99 \pm 0.01^{\mathrm{a}}$ & $1.20 \pm 0.13^{\mathrm{a}}$ & $39.96 \pm 0.67^{\mathrm{d}}$ & $232.58 \pm 0.09^{\mathrm{b}}$ \\
\hline \multirow[t]{6}{*}{ RR } & BS & $10.22 \pm 0.01^{\mathrm{d}}$ & $3.52 \pm 1.04^{\mathrm{c}}$ & $2.39 \pm 0.10^{\mathrm{a}}$ & $0.99 \pm 0.00^{\mathrm{a}}$ & $1.15 \pm 0.17^{\mathrm{d}}$ & $82.89 \pm 1.00^{\mathrm{a}}$ & $362.48 \pm 0.29^{\mathrm{a}}$ \\
\hline & $\mathrm{S}_{24}$ & $32.24 \pm 0.58^{\mathrm{ab}}$ & $6.48 \pm 0.29^{b}$ & $2.77 \pm 0.27^{\mathrm{a}}$ & $0.99 \pm 0.00^{\mathrm{a}}$ & $1.36 \pm 0.11^{\mathrm{cd}}$ & $57.52 \pm 0.90^{c}$ & $302.19 \pm 0.18^{\mathrm{b}}$ \\
\hline & $\mathrm{S}_{24}+\mathrm{G}_{12}$ & $30.01 \pm 0.13^{\mathrm{bc}}$ & $7.56 \pm 0.93^{\mathrm{b}}$ & $2.69 \pm 0.18^{a}$ & $0.99 \pm 0.00^{\mathrm{a}}$ & $1.38 \pm 0.26^{\mathrm{cd}}$ & $58.75 \pm 0.68^{\mathrm{bc}}$ & $298.92 \pm 0.03^{\mathrm{b}}$ \\
\hline & $\mathrm{S}_{24}+\mathrm{G}_{24}$ & $30.71 \pm 0.28^{\mathrm{bc}}$ & $6.62 \pm 0.52^{\mathrm{b}}$ & $2.80 \pm 1.19^{\mathrm{a}}$ & $0.99 \pm 0.00^{\mathrm{a}}$ & $1.6 \pm 0.02^{\mathrm{bc}}$ & $58.89 \pm 0.91^{\mathrm{bc}}$ & $280.75 \pm 0 . .14^{\mathrm{b}}$ \\
\hline & $\mathrm{S}_{24}+\mathrm{G}_{36}$ & $31.04 \pm 0.70^{\mathrm{bc}}$ & $4.39 \pm 0.81^{\mathrm{c}}$ & $2.49 \pm 0.17^{\mathrm{a}}$ & $1.00 \pm 0.02^{\mathrm{a}}$ & $2.01 \pm 0.11^{\mathrm{ab}}$ & $61.07 \pm 1.50^{\mathrm{b}}$ & $276.21 \pm 0.07^{\mathrm{b}}$ \\
\hline & $\mathrm{S}_{24}+\mathrm{G}_{48}$ & $33.37 \pm 1.12^{\mathrm{a}}$ & $10.46 \pm 0.49^{\mathrm{a}}$ & $2.62 \pm 0.41^{\mathrm{a}}$ & $0.99 \pm 0.00^{\mathrm{a}}$ & $2.02 \pm 0.13^{\mathrm{a}}$ & $52.56 \pm 1.50^{\mathrm{d}}$ & $267.55 \pm 0.09^{\mathrm{b}}$ \\
\hline \multirow[t]{6}{*}{ Adlay } & BS & $8.48 \pm 0.04^{\mathrm{f}}$ & $9.90 \pm 0.12^{b}$ & $4.34 \pm 0.11^{\mathrm{d}}$ & $1.97 \pm 0.01^{\mathrm{a}}$ & $2.25 \pm 0.17^{\mathrm{e}}$ & $76.31 \pm 0.03^{\mathrm{a}}$ & $383.90 \pm 0.12^{\mathrm{a}}$ \\
\hline & $\mathrm{S}_{24}$ & $16.45 \pm 0.08^{\mathrm{e}}$ & $14.35 \pm 0.13^{b}$ & $5.63 \pm 0.06^{c}$ & $1.97 \pm 0.01^{\mathrm{a}}$ & $2.66 \pm 0.11^{\mathrm{d}}$ & $62.60 \pm 0.09^{\mathrm{b}}$ & $358.47 \pm 0.03^{\mathrm{b}}$ \\
\hline & $\mathrm{S}_{24}+\mathrm{G}_{12}$ & $21.48 \pm 0.14^{\mathrm{d}}$ & $17.40 \pm 0.12^{\mathrm{a}}$ & $5.76 \pm 0.04^{\mathrm{bc}}$ & $1.97 \pm 0.01^{\mathrm{a}}$ & $3.15 \pm 0.26^{c}$ & $54.40 \pm 0.06^{\mathrm{c}}$ & $339.04 \pm 0.10^{c}$ \\
\hline & $\mathrm{S}_{24^{+}} \mathrm{G}_{24}$ & $23.57 \pm 0.08^{\mathrm{c}}$ & $16.78 \pm 0.15^{\mathrm{a}}$ & $5.94 \pm 0.04^{\mathrm{b}}$ & $1.98 \pm 0.01^{\mathrm{a}}$ & $3.26 \pm 0.02^{\mathrm{bc}}$ & $52.73 \pm 0.15^{\mathrm{d}}$ & $331.5 \pm 0.02^{\mathrm{c}}$ \\
\hline & $\mathrm{S}_{24^{+}} \mathrm{G}_{36}$ & $27.51 \pm 0.16^{\mathrm{b}}$ & $15.69 \pm 0.15^{\mathrm{b}}$ & $6.19 \pm 0.06^{\mathrm{a}}$ & $1.98 \pm 0.01^{\mathrm{a}}$ & $3.31 \pm 0.11^{\mathrm{b}}$ & $49.63 \pm 0.10^{\mathrm{e}}$ & $316.99 \pm 0.05^{\mathrm{d}}$ \\
\hline & $\mathrm{S}_{24^{+}} \mathrm{G}_{48}$ & $32.5 \pm 0.06^{\mathrm{a}}$ & $17.37 \pm 0.14^{\mathrm{a}}$ & $6.63 \pm 0.10^{\mathrm{a}}$ & $1.98 \pm 0.01^{\mathrm{a}}$ & $3.62 \pm 0.13^{\mathrm{a}}$ & $42.52 \pm 0.18^{\mathrm{f}}$ & $299.23 \pm 0.07^{\mathrm{e}}$ \\
\hline
\end{tabular}

Values represent mean \pm standard error. The experiments were carried out 3 times separately. In each row sample means not having the same letter are significantly different (Turkey's multiple comparison test $(\mathrm{P}<0.05)$ ). BS-Before soaking; $\mathrm{S}_{24}-24 \mathrm{~h}$ soaking; $\mathrm{S}_{24}+\mathrm{G}_{12}-24 \mathrm{~h}$ soaking $+12 \mathrm{~h}$ germination; $\mathrm{S}_{24}+\mathrm{G}_{24}-24 \mathrm{~h}$ soaking +24 h germination; $\mathrm{S}_{24}+\mathrm{G}_{36}-24 \mathrm{~h}$ soaking $+36 \mathrm{~h}$ germination; $\mathrm{S}_{24}+\mathrm{G}_{48}-24 \mathrm{~h}$ soaking $+48 \mathrm{~h}$ germination. PR- Purple Rice; RR- Red Rice. db- dry basis. 
These phenolic compounds can also be transformed into flavonoids and lignins with some other compounds [25]. Additionally, some processing conditions such as the frequent washing of rice varieties and soaking may cause some soluble phenols being leaching out [32]. These could relate to the decrease in TPC in some of the soaked and germinated samples in PR and $\mathrm{RR}$, and consequently increase in TFC as reported in this study. A similar observation was reported by Bulatao and Romero [33], who recorded a significant reduction (from 21 to 28\%) in the TPC of black rice after germination. Nonetheless, the values for TPC recorded in both $\mathrm{PR}$ and RR were far higher than those reported for black rice, black sticky rice, and red rice from Thailand ( 0.15 to $0.21 \mathrm{mg} \mathrm{GAE} \mathrm{g}^{-1}$ ) [34]. The TPC values recorded in this study are also similar to those recorded by $\mathrm{Xu}$ et al. [35], where they observed TPC in germinated rough Adlay seeds from 1171.0 to $1850.4 \mu \mathrm{g} \mathrm{GAE} \mathrm{g}^{-1}$ ). Several studies observed changes in the phenolic contents and profiles during germination but virtually none during soaking period. Therefore, this study revealed that changes in the seed composition and phenolic contents composition do not only take place during germination but also during soaking condition. The results of this study support the results of the report of Vichapong et al. [36], who revealed high values for phenolic compounds in pigmented rice varieties. The phenolic concentrations reported in this study in both rice varieties were higher than those reported by Sompong et al. [30] where they recorded ranges between 7.4 to $10.5 \mathrm{mg} \mathrm{g}^{-1}$ for black rice varieties and 1.4 to $3.4 \mathrm{mg} \mathrm{g}^{-1}$ for red rice. In contrast to this study, ferullic acid and proto-catechuic acid were the predominant compounds detected in red rice. This variation in the phenolic composition could be due to different the rice varieties, germination locations, conditions, and time. The phenolic profile observed in adlay in this study is similar to the report of Xu et al. [35], where they also identified caffeic acid vanillic acid, $P$-coumaric, and ferullic acid in germinated adlay seeds.

\section{The antioxidant activity of un-germinated, soaked and germinated extracts}

The antioxidant capacity is closely interrelated to the phenolic contents of the evaluated samples [37]. The antioxidant capacity is closely interrelated to the phenolic contents of the evaluated samples. Antioxidants are compounds with the potential of preventing lipid peroxidation that may trigger cancer and heart disease [29]. The results from the antioxidant activity of the samples from this study determined by DPPH, ABTS, and FRAP assays are shown in Figure 2. Soaking and germination conditions led to an increase in the antioxidant activities in all the samples $(\mathrm{P}<0.05)$ except for $\mathrm{RR}$, where only the soaking condition increase the antioxidant capacity in ABTS assay. In this study, PR contained phenolic compounds at maximum concentrations with ranges between $29.77 \pm 0.03$ to $48.04 \pm 0.06$ in DPPH, $16.18 \pm 0.11$ to $29.09 \pm 0.08$ in ABTS and $22.13 \pm 0.11$ to $47.97 \pm 0.04$ in FRAP assays, which may highly contribute to the strongest antioxidant activity of the rice variety. Adlay seeds recorded the least antioxidant capacities in all the assays. Other studies have also revealed that germination positively affected the antioxidant properties of rice varieties and pigmented rice samples proved to have better antioxidant capacities than the white samples [33]. Sompong et al. [30] also reported that pigmented Thai rice varieties generally had better ferric reducing properties than other Chinese and Sri Lankan varieties evaluated. In their study, the black rice samples showed higher FRAP values with a mean of $5.6 \mathrm{mmol} \mathrm{FE} \mathrm{(II)/100g.} \mathrm{However,} \mathrm{in} \mathrm{the} \mathrm{study} \mathrm{on}$ Adlay seeds by Xu et al. [35], total ABTS and FRAP values reduced during the first $24 \mathrm{~h}$ and increases until $60 \mathrm{~h}$. These results are similar to the results obtained from this study, except for the reduction within the first $24 \mathrm{~h}$ which could be as a result of the difference in germination conditions and varieties. 
Identification of phenolic profiles un-germinated, soaked and germinated extracts

The phenolic compounds detected in this study are presented in Table 3 and the phenolic standards and profiles in Figure 3. There were 9 compounds detected in PR, 6 in RR, and 6 in adlay. Gallic acid, proto-catechuic acid, catechin, caffeic acid, $P$-coumaric and ferullic acid were all detected in both PR and RR. Proto-catechuic acid, catechin, caffeic acid were the dominant compounds in PR and catechin in RR. Similar to the purple rice variety, caffeic acid, vanillin, $P$-coumaric and ferullic acid, rutin trihydrate and trans-cinnamic were also identified in adlay with rutin trihydrate at highest concentrations among the compounds. Germination resulted in the synthesis of gallic acid in both rice varieties. Additionally, caffeic acid and catechin were synthesized during germination in the RR. Similarly, germination led to the production of vanillin in adlay seeds. From the results in this study, PR contained the highest concentrations for phenolic compounds (from $8.14 \pm 0.07$ to $11.86 \pm 0.06 \mathrm{mg} \mathrm{g}^{-1}$ ) with the highest values observed during soaking and $36 \mathrm{~h}$ germination condition. This was followed by $\mathrm{RR}$ $\left(2.16 \pm 0.18\right.$ to $\left.8.02 \pm 0.21 \mathrm{mg} \mathrm{g}^{-1}\right)$ where the soaking condition recorded the highest phenolic compounds. Adlay extracts contained the least phenolic compounds concentrations $(1.10 \pm 0.08$ to $2.07 \pm 0.11$ ) and the highest values were recorded at $24 \mathrm{~h}$ and $36 \mathrm{~h}$ germination period. These results attest to the values recorded in the PR where $2 \mathrm{~h}$ soaking and $36 \mathrm{~h}$ germination condition gave the highest values for TPC and TFC, the $24 \mathrm{~h}$ soaking condition in RR and $24 \mathrm{~h}$ germination in adlay in this study. During soaking and germination process, the activities of some amylolytic and proteolytic enzymes results into softening the structure of the kernel, thereby aiding the release of phenolic compounds. However, the oxidation of some phenolic substrates could also cause a reduction in some phenolic compounds as phenoloxidase and peroxidase enzymes resume activities [38]. This may explain the increase and decrease in some of the compounds during soaking and germination conditions.

\section{Correlation between phenolics and antioxidant activity}

The antioxidant activities were positively correlated with the total phenolic and flavonoid compounds before germination, during soaking and germination periods (Table 4). In PR, only the total flavonoid contents were correlated with the antioxidant activities $(\mathrm{P}<0.01)$. In contrast, the TPC in the red variety were correlated with TPC and activities from ABTS assay $(\mathrm{P}<0.01)$, while the TFC correlated with antioxidants activities from DPPH and FRAP $(\mathrm{P}<0.05)$ and ABTS $(\mathrm{P}<0.01)$. However, in adlay seeds, the TFC and TPC were all correlated with the activities from all assays $(\mathrm{P}<0.01)$. A strong correlation was found between TFC and ABTS assay in the red rice $(\mathrm{P}<0.01, \mathrm{r}=0.978)$ and adlay seeds $(\mathrm{P}<0.01, \mathrm{r}=0.97)$. In other studies about rice varieties, red rice was recorded to have the greatest ABTS scavenging capacity [30]. According to Awika et al. [39], ABTS assay is proven to be a flexible method of estimating free radical scavenging activities. Additionally, the assay can also evaluate the antioxidant activities in hydrophilic as well as lipophilic compounds. High correlations between ORAC, ABTS, FRAP, and the phenolic contents ( $\mathrm{r}=0.9979,0.9765$, and 0.9607 respectively) and total flavonoid contents ( $r=0.9798,0.9868$ and 0.9745 , respectively) were extensively reported in adlay seeds [35]. 

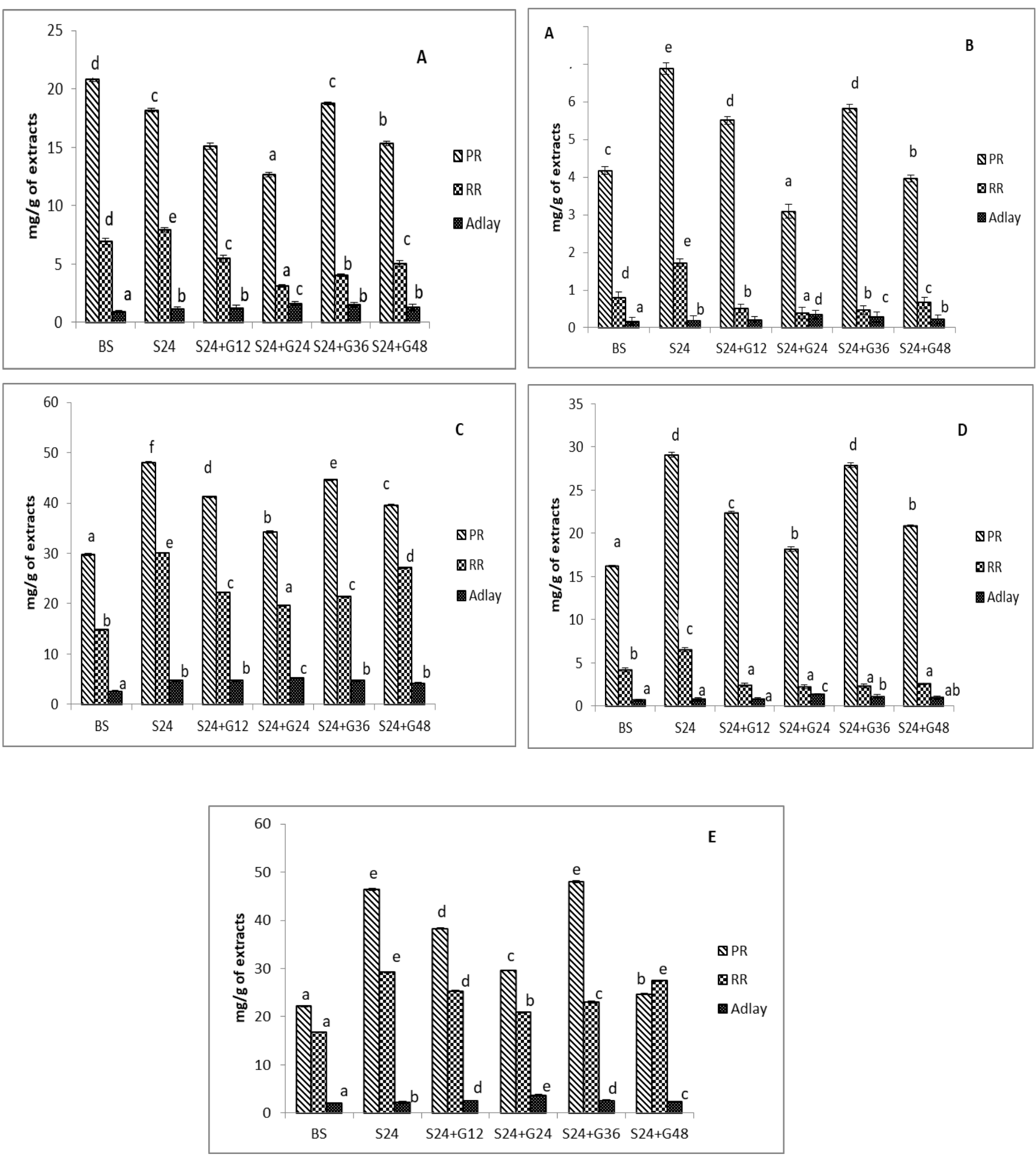

Figure 2. A- Total Pheolic Contents (TPC), B- Total Flavonoid Contents and antioxidant properties (C- DPPH; D- ABTS; E- FRAP) of PR, RR, and Adlay before soaking, at 24h soaking and germination periods.BS-Before soaking; $\mathrm{S}_{24-} 24 \mathrm{~h}$ soaking; $\mathrm{S}_{24}+\mathrm{G}_{12}-24 \mathrm{~h}$ soaking +12 h germination; $\mathrm{S}_{24}+\mathrm{G}_{24}-24 \mathrm{~h}$ soaking $+24 \mathrm{~h}$ germination; $\mathrm{S}_{24}+\mathrm{G}_{36}-24 \mathrm{~h}$ soaking $+36 \mathrm{~h}$ germination; $\mathrm{S}_{24}+\mathrm{G}_{48}-24 \mathrm{~h}$ soaking $+48 \mathrm{~h}$ germination. PR- Purple Rice. RR- Red Rice. TPC (mg GAE/g), TFC (mg CAE/g), DPPH, ABTS, FRAP (mg TE/g). 
Table 3. Polyphenolic components and concentrations ( $\mathrm{mg} \mathrm{g}^{-1}$ dry weight) of extracts during soaking and germination periods

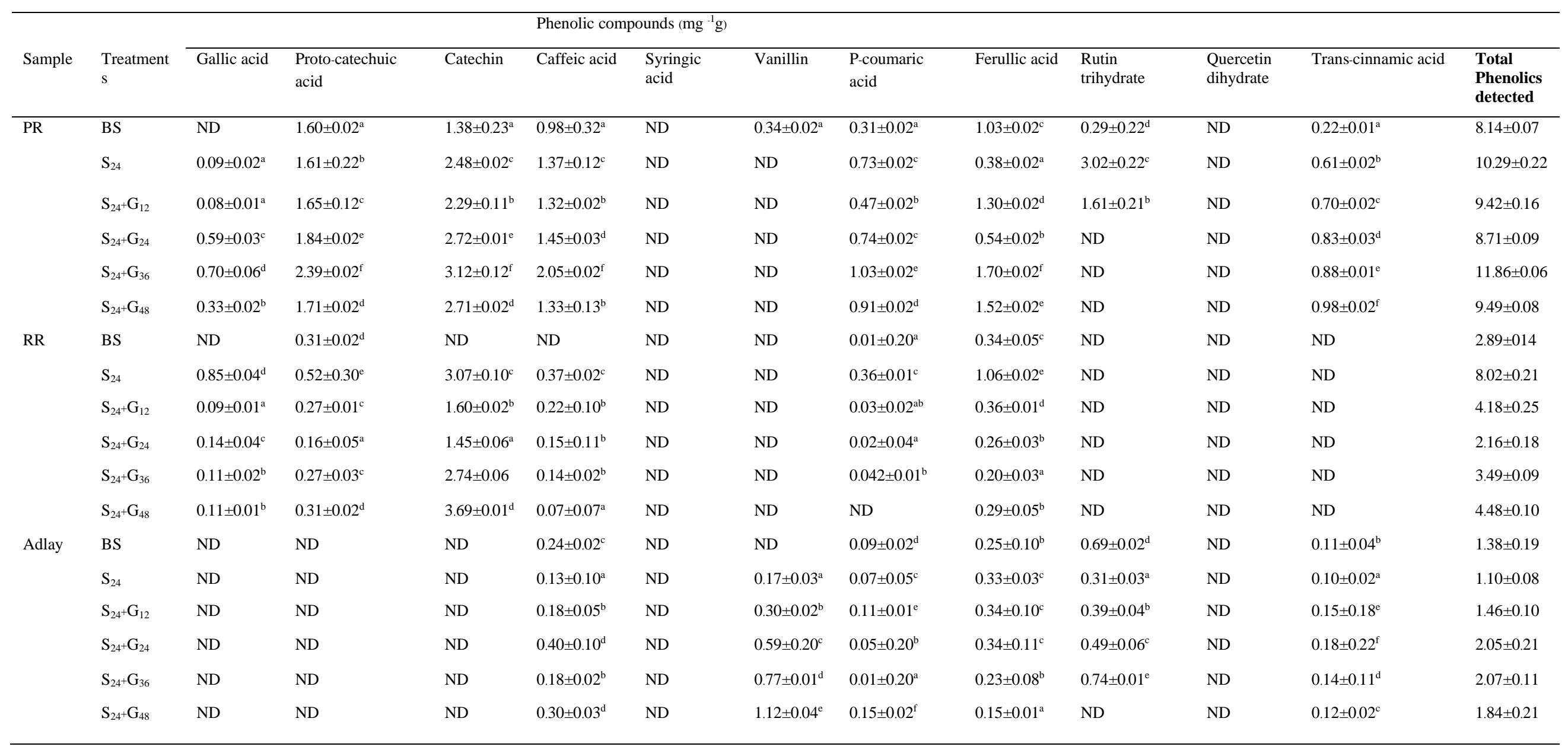

Values represent mean \pm standard error. The experiments were carried out in triplicate. In each row, sample means not having the same letter are significantly different (Turkey's multiple comparison test $(\mathrm{P}<0.05)$ ). BS-Before soaking; S24- 24 h soaking; S24+G12- 24 h soaking +12 h germination; S24+G24 -24 h soaking +24 h germination; S24+G36- 24 h soaking +36 h germination; S24+G48- 24 h soaking +48 h germination. PR- Purple Rice; RR- Red Rice. 

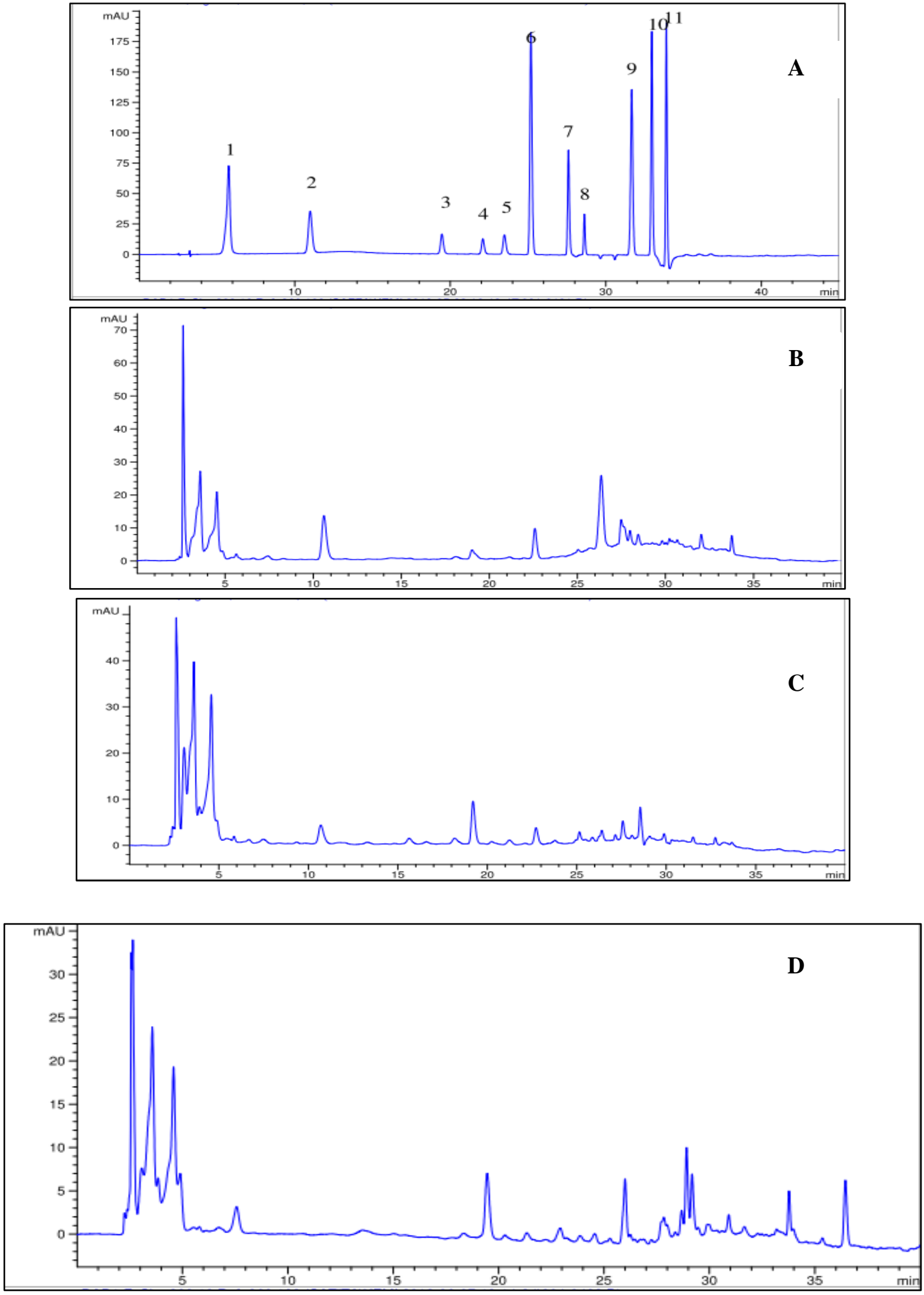

Figure 3. High Performance Liquid Chromatography (HPLC) chromatograms of phenolic compounds. A- Standards; 1: Gallic Acid; 2: Protocatechuic Acid; 3: Catechin; 4: Caffeic Acid; 5: Syringic Acid; 6: Vanillin; 7: P-Coumaric Acid; 8: Ferulic Acid; 9: Rutin Trihydrate; 10: Quercetin Dihydrate; 11: Trans-cinnamic Acid. B- Purple rice at $24 \mathrm{~h}$ soaking. C- Red rice at 24 h soaking. D- Adlay at 24 h germination. 
Table 4. Pearson correlation between total phenolic, total flavonoid contents and antioxidants properties of un-germinated and germinated PR, RR and Adlay

\begin{tabular}{|c|c|c|c|c|c|c|}
\hline \multirow[b]{2}{*}{ Antioxidant activity } & \multicolumn{2}{|c|}{ PR } & \multicolumn{2}{|c|}{$\mathbf{R R}$} & \multicolumn{2}{|c|}{ Adlay } \\
\hline & TPC & TFC & TPC & TFC & TPC & TFC \\
\hline $\mathrm{DPPH}$ & 0.22 & $0.80 * *$ & 0.28 & $0.59 * *$ & $0.80 * *$ & $0.64 * *$ \\
\hline ABTS & 0.20 & $0.88^{* *}$ & $0.89^{* *}$ & $0.98^{* *}$ & $0.97 * *$ & $0.97 * *$ \\
\hline FRAP & 0.13 & $0.85 * *$ & 0.23 & $0.48 *$ & $0.84 * *$ & $0.91 * *$ \\
\hline
\end{tabular}

\section{CONCLUSION}

Prevention of occurrences of some prevalent diseases is more effective than curing. Therefore, consumption of functional foods high in polyphenols and antioxidants could be helpful in human health. From this study, soaking especially and some germination conditions led to an increase in the nutritional values, polyphenolic and antioxidant properties in evaluated samples. Adlay though contains polyphenolic contents at lower concentrations compared with the pigmented rice varieties, the higher protein and fat contents it contains could be exceptional functional foods when combined with the rice varieties. Interestingly, the PR is an excellent source of polyphenols and flavonoids improved by soaking and germination conditions. Various food products derived from these cereals may not only help to prevent some various diseases in humans but also improve the market for these indigenous pigmented rice varieties and adlay. Development of bioactive compounds from them could as well be an exquisite source of functional food products and nutraceuticals.

List of Abbreviations: Purple rice (PR); red rice (RR); Gamma-aminobutyric acid (GABA); Association of Official Analytical Chemists (AOAC); Total extractable phenolic content (TPC); Total extractable flavonoid content (TFC); 2,2-diphenyl-1-picryl hydrazyl (DPPH); 2,2-azino-bis-3-ethylbenzthiazoline-6-sulphonic acid (ABTS); Ferric reducing antioxidant power (FRAP); 2, 4, 6- tripyridyl-s-triazine (TPTZ).

Competing Interests: There are no conflicts of interest to declare.

Author Contributions: Iyiola Oluwakemi Owolabi conducted the research and wrote the manuscript. Bandhita Saibandith advised the research. Santad Wichienchot gave guidelines during the research and vetted the manuscript. Chutha Takahashi Yupanqui supervised, read, and approved the final version of the manuscript.

Acknowledgments and Funding: The support of the Higher Education Research Promotion and Thailand's Education Hub for the Southern Region of Asian Countries Project office of the Higher Education Commission in granting a scholarship (Grant number - 020/2016) to pursue post-graduate studies is acknowledged. The authors are also grateful to Prince of 
Songkla University Fiscal Research Budget (Grant number PHY610118S). We also acknowledge the graduate school of Prince of Songkla University, Thailand for awarding the Graduate school Dissertation Funding.

\section{REFERENCES}

1. Wu F, Yang N, Toure A, Jin Z, Xu X: Germinated brown rice and its role in human health. Crit Rev Food Sci Nutr 2013, 53: 451-463.

2. Moongngarm A, Saetung N: Comparison of chemical compositions and bioactive compounds of germinated rough rice and brown rice. Food Chem 2010, 122: 782788.

3. Friedman M: The nutritional value of proteins from different food sources. J Agric Food Chem 1996, 43 :3-29.

4. Kang MY, Rico CW, Bae HJ, Lee SC: Antioxidant capacity of newly developed pigmented rice cultivars in Korea. Cereal Chem 2013, 90:497-501.

5. Min B, McClung AM, Chen MH: Phytochemicals and antioxidant capacities in rice brans of different color. J Food Sci 2011, 76: C117-C126.

6. Deng GF, Xu XR, Zhang Y, Li D, Gan RY, Li HB: Phenolic compounds and bioactivities of pigmented rice. Crit Rev Food Sci Nut 2013, 53: 296-306.

7. Frank T, Reichardt B, Shu Q, Engel KH: Metabolite profiling of colored rice (Oryza sativa L.) grains. J Cereal Sci 2012, 55: 112-119.

8. Ling WH, Cheng QX, Ma J, Wang T: Red and black rice decrease atherosclerotic plaque formation and increase antioxidant status in rabbits. J Nutr 2001, 131: 14211426.

9. Patil SB, Khan MK: Germinated brown rice as a value added rice product: A review. J Food Sci Technol 2011, 48(6): 661-667.

10. Zhao MD, Sun-Waterhouse D, Su G, Lin L, Wang X, Dong Y: In vitro and in vivo studies on adlay-derived seed extracts: phenolic profiles, antioxidant activities, serum uric acid suppression, and xanthine oxidase inhibitory effects. J Agric Food Chem 2014 62: 7771-7778.

11. Manosroi J, Khositsuntiwong N, Manosroi A: Biological activities of fructo oligosaccharide (FOS)-containing Coix lachryma-jobi Linn. extract. J Food Sci Technol 2014, 51:341-346.

12. Lu X, Liu W, Wu J, Li M, Wang J, Wu J, Luo C: A polysaccharide fraction of adlay seed (Coix lachryma-jobi L.) induces apoptosis in human non-small cell lung cancer A549 cells. Biochem Biophys Res Commun 2013, 430: 846-851.

13. Chang HC, Huang YC, Hung WC: Antiproliferative and chemopreventive effects of adlay seed on lung cancer in vitro and in vivo. J Agric Food Chem 2003, 51(12): 3656-3660.

14. Chen HJ, Chung CP, Chiang W, Lin YL: Anti-inflammatory effects and chemical study of a flavonoid-enriched fraction from adlay bran. Food Chem 2011, 126(4):1741-1748. 
15. Lin Y, Tsai CE: A study of adlay on lowering serum and liver lipids in hamsters. J Food Lipids 2008, 15(2): 176-189.

16. Huang BW, Chiang MT, Yao HT, Chiang W: The effect of adlay oil on plasma lipids, insulin and leptin in rat. Phytomedicine 2005: 12:433-439.

17. AOAC: Official Method of Analysis. Association of Official Analytical Chemists 17th ed, Washington DC; 2000.

18. Sofowora A: Medicinal plants and traditional medicine in Africa. Ibadan, Nigeria: Spectrum Books; 1993.

19. Harborn, J: Phytochemical methods. London: Chapman and Hall Ltd; 1973.

20. Singleton V, Rossi JA: Colorimetry of Total Phenolics with PhosphomolybdicPhosphotungstic Acid Reagents. Am J Enol Viticul 1965, 16: 144-158.

21. Brand-Williams W, Cuvelier ME, Berset C: Use of a free radical method to evaluate antioxidant activity. LWT-Food Sci Technol 1995, 28: 25-30.

22. Arnao MB, Cano A, Acosta M: The hydrophilic and lipophilic contribution to total antioxidant activity. Food Chem 2001, 73: 239-244.

23. Benzie IF, Strain J: The ferric reducing ability of plasma (FRAP) as a measure of "antioxidant power": the FRAP assay. Anal Biochem 1996, 239: 70-76.

24. Puangwerakul Y: Malt Characteristic of 40 Rice Varieties Cultivated in Thailand. Kasetsart J (Nat. Sci.) 2007, 41: 15-20.

25. Zhang G, Xu Z, Gao Y, Huang X, Zou Y, Yang T: Effects of germination on the nutritional properties, phenolic profiles, and antioxidant activities of buckwheat. $\mathrm{J}$ Food Sci 2015, 80(5): H1111-H1119.

26. Hettiarachchy NS: Effects of germination on nutrient composition of long grain rice and its physico-chemical and functional proteins. J Food Nutr 2014, 1: 1-9.

27. Juliano BO: Rice Chemistry and Quality. Muñoz, Nueva Ecija, Philippines: Philippine Rice Research Institute; 2007: 402.

28. Chaisiricharoenkul J, Tongta S, Intarapichet KO: Structure and chemical and physicochemical properties of Job's tear (Coix lacryma-jobi L.) kernels and flours. J Sci Technol 2011, 18(2): 109-122.

29. Ohtsubo K, Suzuki K, Yasui Y, Kasumi T: Bio-functional components in the processed pre-germinated brown rice by a twin-screw extruder. J Food Compost Anal 2005, 18 (4): 303-316.

30. Sompong R, Siebenhandl-Ehn S, Linsberger-Martin G, Berghofer E: Physicochemical and antioxidative properties of red and black rice varieties from Thailand, China and Sri Lanka. Food Chem 2011, 124(1): 132-140.

31. Oko AO, Ubi BE, Efisue AA, Dambaba N: Comparative analysis of the chemical nutrient composition of selected local and newly introduced rice varieties grown in Ebonyi State of Nigeria. Int J Agric Forest 2012, 2(2): 16-23.

32. Chanphrom P: Antioxidants and antioxidant activities of pigmented rice varieties and rice bran. PhD thesis. Mahidol University, Thailand; 2007: 123. 
33. Bulatao RM, Romero MV: Effects of Germination on the Proximate Composition, Antioxidant Property and Eating Quality of Brown Rice (Oryza sativa L.). Philipp Agric Sci 2014, 97(1): 19-27.

34. Htwe NN, Srilaong V, Tanprasert K, Uthairatanakij A, Kanlayanarat S: Characterization of bioactive compounds in black and red pigmented cultivars in Thailand. In Proc Asia-Pacific Symposium on Assuring Quality and Safety of Foods. Edited by Kanlayanarat S et al. Bangkok, Thailand; 2009. ISHS Acta Horticulture 2009, 837: 65-71.

35. Xu L, Wang P, Ali B, Yang N, Chen Y, Wu F, Xu X: Changes of the phenolic compounds and antioxidant activities in germinated adlay seeds. J Sci Food Agric 2017, 97(12): 4227-4234.

36. Vichapong J, Sookserm M, Srijesdaruk V, Swatsitang P, Srijaranai S: High performance liquid chromatographic analysis of phenolic compounds and their antioxidant activities in rice varieties. LWT-Food Sci Technol 2010, 43: 1325-1330.

37. Elzaawely AA, Tawata S: Antioxidant activity of phenolic rich fraction obtained from Convolvulus arvensis L. leaves grown in Egypt. Asian J Crop Sci 2012, 4:3240.

38. Kaukovirta-Norj A, Wihelmson A, Poutanen K: Germination: A means to improve the functionality of oat. Agric. Food Sci 2008, 13: 100-112.

39. Awika JM, Rooney LW, Wu X, Prior RL, Cisneros-Zevallos L: Screening methods to measure antioxidant activity of sorghum (Sorghum bicolor) and sorghum products. J Agric Food Chem 2003, 51: 6657-6662. 